\title{
Long Term and Recent Secular Variation of the Geomagnetic Dipole Moment
}

\author{
Leroy R. Alldredge \\ U.S. Geological Survey \\ Denver, Colorado, U.S.A. \\ (Received March 20, 1983)
}

\section{Introduction}

The very large collection of geomagnetic spherical harmonic models tabulated by BARRACLOUGH (1978) facilitates a look at the long term changes in the dipole moment of the Earth. Barraclough has tabulated the spherical harmonic coefficients of 264 models for epochs from 1550 to 1970 . All of these analyses were made since 1839.

It is easy to show that the strength, $\mathrm{M}$, of the geomagnetic dipole moment, normalized by dividing by the cube of the Earth's radius $R$, is given by

$$
\frac{M}{R^{3}}=\left[\left(g_{1}^{0}\right)^{2}+\left(g_{1}^{1}\right)^{2}+\left(h_{1}^{1}\right)^{2}\right]^{1 / 2}
$$

where the $g$ 's and $h$ 's are the first-degree spherical harmonic coefficients. This quantity will be referred to simply as the magnetic moment in what follows. The magnetic moment for each of the models tabulated by Barraclough is included within the limits of the vertical bars for each epoch in Fig. 1. The mean value for each epoch is shown by an $X$ and the median value is shown by a $\square$.

Figure 2 shows quadratic curves that were fitted by least squares to the median values og Fig. 1, slightly modified as described in the legend to Fig. 2.

\section{Discussion}

As expected, the spread of values for early epochs is much larger than for recent epochs as seen in Fig. 1. In spite of this, the well known downward trend in the magnetic moment seems to have persisted throughout the entire period (see both figures).

The slopes of the curves in Fig. 2 for 1980 are:

Curve a $-15.6 \mathrm{nT} / \mathrm{yr}$.

b $-19.5 \mathrm{nT} / \mathrm{yr}$. 


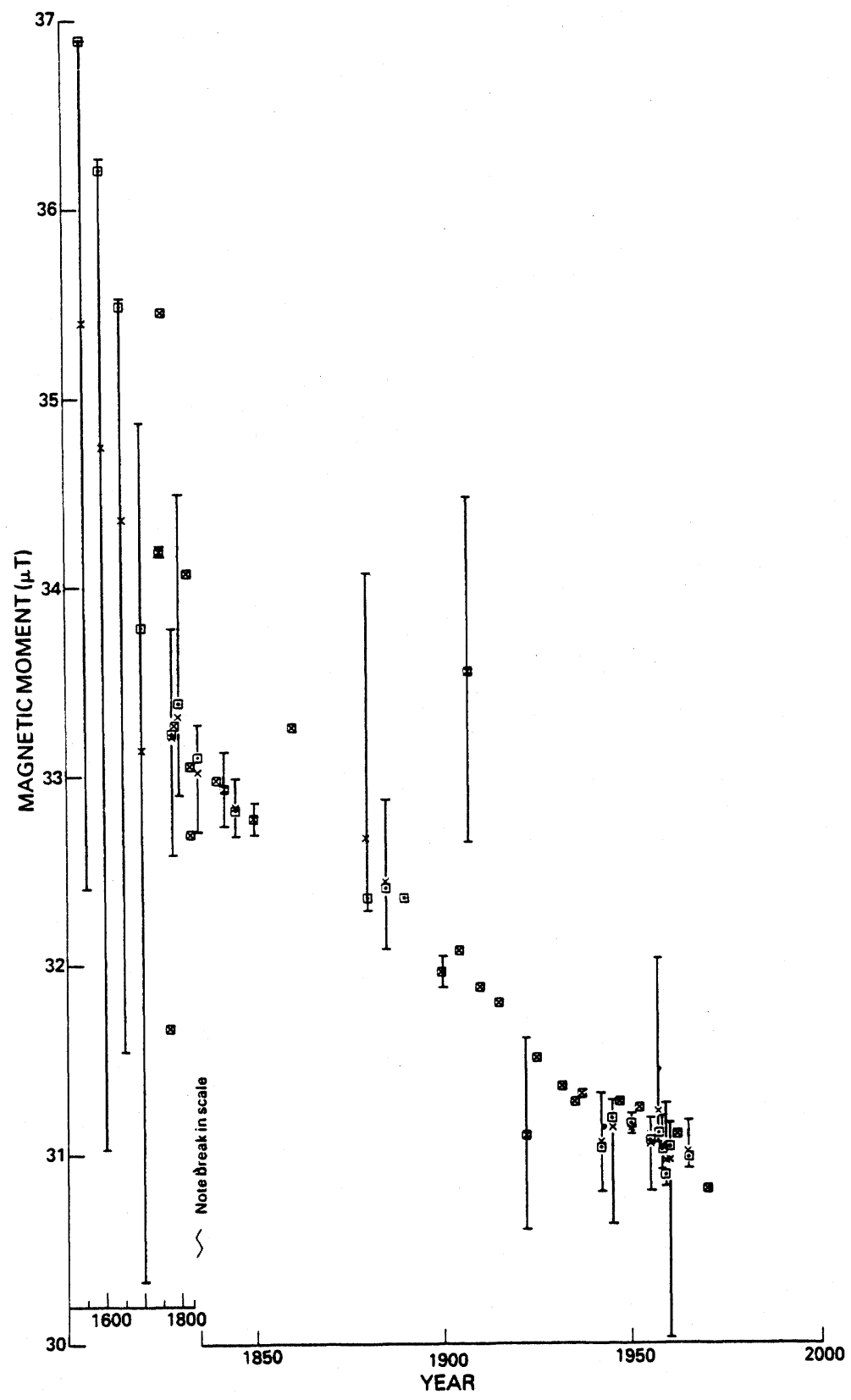

Fig. 1. Magnetic moment of the Earth as a function of time. Every value derivable from the spherical harmonic analyses reported by BARRACLOUGH (1978) is included with the limits of the vertical bars for each epoch where more than one analysis was reported for a given epoch. The X's mark the mean ans the $\square$ mark the mediam value for each epoch. Note the break in the time scale at 1830 . 


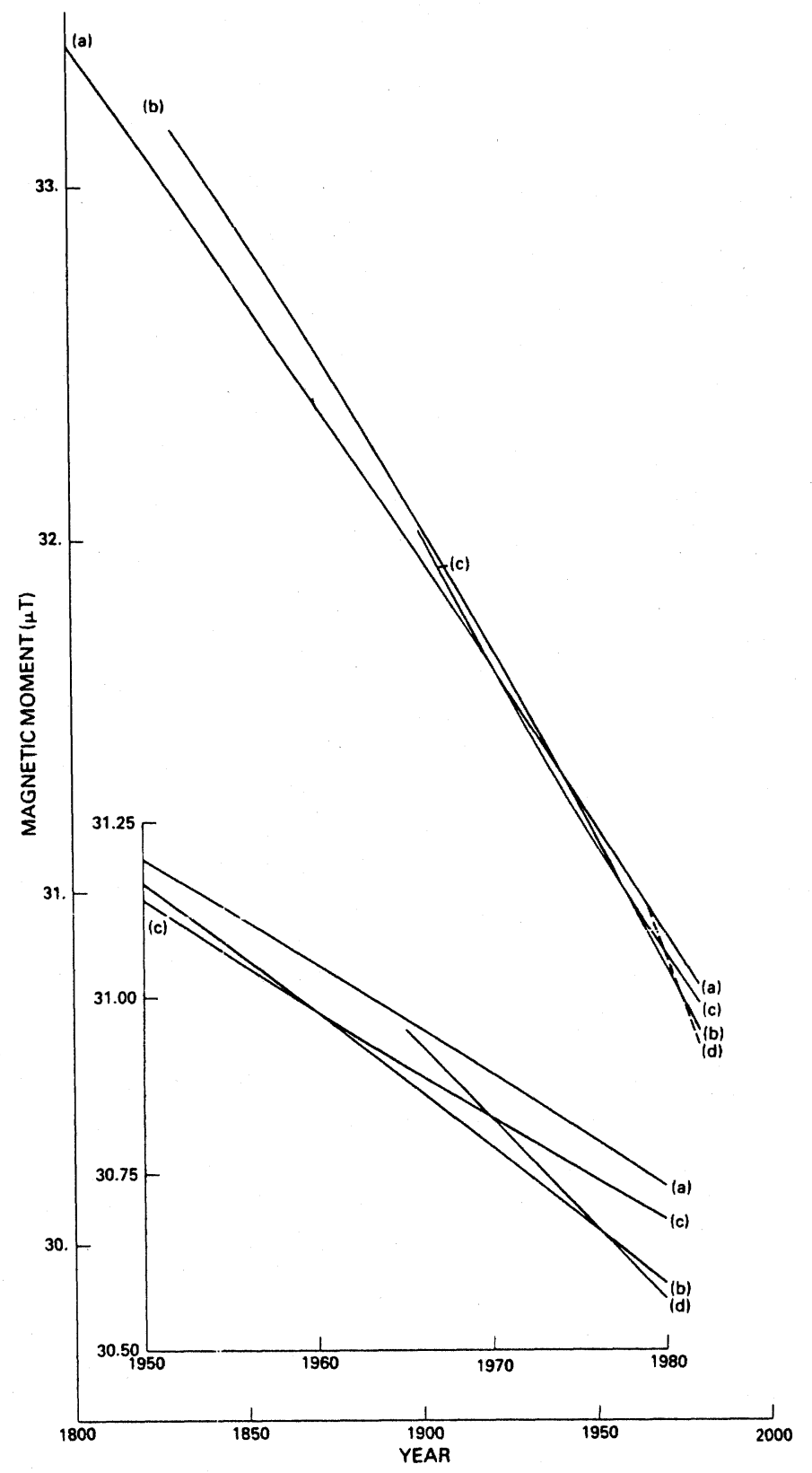

Fig. 2. Magnetic moment of the Earth as fitted by a quadratic by least squares to the median values of Fig. 1 after omitting the outlying values for 1907 and 1922, which were derived from analyses that included only a very few terms; changing the values for 1965 and 1970 to match those chosen by IAGA at Edinburgh in 1981 as definitive models for those epochs; and adding values for 1975 and 1980 as chosen by IAGA at Edinburgh (IAGA Division 1, WorkING Group 1, 1981). Curve (a) is a fit for all of the adjusted data, curve (b) is a fit to data from 1830 onward, curve (c) is a fit to data from 1900 onward, and curve (d) is a fit to data from 1965 onward. The inset curves amplify the scales following 1950 . 


$$
\text { c }-14.3 \mathrm{nT} / \mathrm{yr} \text {. }
$$

All of the curves showed a downward curvature except curve $\mathrm{c}$ which was slightly upward. It is doubtful that the slight curvatures are statistically significant in view of the uncertainty in the data, although the general acceleration of the decrease in the magnetic moment was pointed out by LEATON and MALIN (1967).

The last four values used in the above fitting procedure are shown in the second column of Table 1 . These four values should yield the very best available estimates of the recent and current secular variation in the magnetic moment. The values for 1965,1970 , and 1975 were derived from models adopted by IAGA at the Edinburgh 1981 Scientific Assembly as definitive, which means they represent the best models thought to be possible because presumably, all data that will ever be available for these epochs was used in their derivations. The 1980 model leans very heavily on Magsat data and is nearly equal to the Magsat model published by LANGEL et al. (1980), in which an effort was made to exclude solar-cycle effects.

The least-squares quadratic fit to these four values is indicated in column 3 in Table 1 . This fit has a slight downward curvature which is probably not statistically significant.

The secular variation of the magnetic moment as determined by the quadratic fit described above is shown in column 5 of Table $\mathbf{I}$.

If the solar-cycle effect was not removed from the data, both the external and internal lst-degree zonal harmonic coefficients would tend to decrease with the sunspot numbers (ALLDREDGE et al., 1979). This would tend to contaminate the apparent internal magnetic moment by decreasing it with the sunspot numbers. The sunspot numbers were very high in 1970 and 1980 and low in 1965 and 1975. It is interesting to note that the "observed" magnetic moments shown in column 2 of Table 1 exceeded the quadratically smoothed values in column 3 in 1970 and 1980 and were less than these values in 1965 and 1975 as shown in column 4, indicating that the solar-cycle effect had been slightly over compensated.

All of the foregoing estimates of the changes in the magnetic moment are based on differences of main field models. Predictive models which contain rates of change of the spherical harmonic coefficients, provide a means of predicting the changes in the dipole moment. Such predictions are likely to be less accurate than those

Table 1. Magnetic moment for four recent models (IAGA Division 1, Working Group 1, 1981).

\begin{tabular}{lllll}
\hline & $\begin{array}{l}\text { Mag. moment from } \\
\text { models adopted by } \\
\text { Date }\end{array}$ & $\begin{array}{l}\text { Mag. moment from } \\
\text { IAGA in Edinburgh }\end{array}$ & $\begin{array}{l}\text { Secular variation } \\
\text { quatic fit }\end{array}$ & $\begin{array}{c}\text { Col. (2)-Col. (3) } \\
\text { inag. moment from } \\
\text { quadratic fit }\end{array}$ \\
\hline 1965 & $30,952 \mathrm{nT}$ & $30,953 \mathrm{nT}$ & $-1 \mathrm{nT}$ & $-25.1 \mathrm{nT} / \mathrm{yr}$. \\
1970 & 30,829 & 30,826 & 3 & -25.4 \\
1975 & 30,696 & 30,699 & -3 & -25.7 \\
1980 & 30,570 & 30,569 & 1 & -26.0 \\
\hline
\end{tabular}


obtained from differences of definitive models. Several predicted changes for various epochs are shown in Table 2.

If we assume that the models recently approved by IAGA (IAGA Division 1, WorkING Group 1, 1981) are accurate, then it follows that the secular variation models used to compute the rate of change of the magnetic moment for 1965 as shown in Table 2 were too low in amplitude and that the models for 1975 in Table 2 were a little too high.

Most models prior to 1960 yielded secular variations of the magnetic moment in the neighborhood of -15 to $-20 \mathrm{nT} / \mathrm{yr}$ as seen by curves (a) to (c) in Fig. 2. This was true whether the secular change was determined by taking the slope of the moment vs. time or was determined separately from differences in annual mean values (see HoDDER, 1981, and MALIN, 1969, for additional magnetic moment values). Most of these earlier analyses relied heavily on poorly distributed observatory data supplemented by rather small repeat station networks. Following World War II more and more intensity measurements became available, and following 1957, satellite data became available, but none of the extensive total field data were used in the models tabulated by BARRACLOUGH (1978) until epoch 1960.

The recent models adopted by IAGA in Edinburgh (IAGA Divison 1, WorKING GrouP 1, 1981) for epoch 1965, 1970, 1975 and 1980 relied heavily on airborne and satellite data which resulted in a much greater rate of decrease in the magnetic moment as shown by Table 1 and curve (d) in Fig. 2. The new secular variation of the magnetic moment from these late models being approximately $-25 \mathrm{nT} / \mathrm{yr}$.

There are several possible reasonable explanations for the high rate of change in the recent values of magnetic moment as compared with earlier values. The difference could be caused by the improved area of data coverage. The difference might be caused by the fact that the later analyses were truncated at a higher degree than earlier analyses. HoDDER (1981) shows examples where the truncation level not only changed the magnetic moment but also changed the secular change of the moment. On the other hand, the continued decrease in the secular change seems to fit very well with the pattern shown by MALIN (1969) using a homogeneous set of observatory data from 1924.5 to 1967.5 during which time the secular change went from $-7 \mathrm{nT}$ to $-17 \mathrm{nT}$.

Table 2. Predicted rates of change in the magnetic moment.

\begin{tabular}{|c|c|c|c|}
\hline Author & Epoch & $\begin{array}{l}\text { Rate of change of the } \\
\text { magnetic moment }\end{array}$ & Comments \\
\hline LEATON et al. (1965) & 1965 & $-15.6 \mathrm{nT} / \mathrm{yr}$ & \\
\hline IAGA COMM. 2, WorKING Group 4 (1969) & 1965 & -16.0 & IGRF, 1965 \\
\hline HuRWITz et al. (1974) & 1970 & -24.3 & \\
\hline HARWOOD and MALIN (1976) & 1975 & -28.8 & \\
\hline IAGA Division 1 Study Group (1976) & 1975 & -27.6 & IGRF, 1975 \\
\hline IAGA Division 1, Working Group 1 (1981) & 1980 & -25.6 & IGRF, 1980 \\
\hline
\end{tabular}




\section{REFERENCES}

Alldredge, L. R., C. O. Stearns, and M. Sugiura, Solar-cycle variation in Geomagnetic external spherical harmonic coefficients, J. Geomag. Geoelectr., 31, 495-508, 1979.

Barraclough, D. R., Spherical harmonic models of the geomagnetic field, Geomag. Bull., 8, Institute of Geological Sciences, U. K., 66 pp, 1978.

Harwood, J. M. and S. R. C. Malin, Present trends in the Earth's magnetic field, Nature, 259, 469-471, 1976.

HodDer, B. M., Geomagnetic secular variation since 1901, Geophys. J. R. Astro. Soc., 65, 763-776, 1981.

Hurwitz, L., E. B. Fabiano, and N. W. Peddie, A model of the geomagnetic field for 1970, J. Geophys. Res., 79, 1716-1717, 1974.

IAGA Comm. 2, W. G. 4, International Geomagnetic reference field 1965.0, J. Geophys. Res., 74, 44074408, 1969.

IAGA Division 1 STUDY Group, International geomagnetic reference field 1975, EOS, 57, 120-121, 1976.

IAGA DIVISION 1, WorkING Group 1, International geomagnetic reference fields : DGRF 1965, DGRF 1970, DGRF 1975 and IGRF 1980, EOS, 62, 1169, 1981.

Langel, R. A., R. H. Estes, G. D. Mead, E. B. Fabiano, and E. R. Lancaster, Initial geomagnetic field model from Magsat vector data, Geophys. Res. Lett., 7, 793-796, 1980.

Leaton, B. R., S. R. C. Malin, and M. J. Evans, An analytical representation of the estimated geomagnetic field and its secular change for the epoch 1965.0, J. Geomag. Geoelectr., 17, 187-194, 1965.

Leaton, B. R. and S. R. C. Malin, Recent changes in the magnetic dipole moment of the Earth, Nature, 213, $1110,1967$.

Malin,S. R. C., Geomagnetic secular variation and its changes, 1942.5 to 1962.5 , Geophys. J. R. Astro. Soc., 17, 415-441, 1969. 